\title{
Growth of mycelial biomass and fruit body cultivation of Lentinus squarrosulus collected from home garden of Tripura in Northeast I ndia
}

\author{
A. Roy Das ${ }^{1}$, M. Borthakur ${ }^{3}$, A.K. Saha ${ }^{1}$, S. R. Joshi ${ }^{3}$, P. Das $^{2 *}$ \\ ${ }^{1}$ Mycology and Plant Pathology Laboratory, Department of Botany, Tripura University, Suryamaninagar-799 022, Tripura, India. \\ ${ }^{2}$ Microbiology Laboratory, Department of Botany, Tripura University, Suryamaninagar-799 022, Tripura, India. \\ ${ }^{3}$ Microbiology Laboratory, Department of Biotechnology and Bioinformatics, North Eastern Hill University, Shillong-793 022, Meghalaya, India.
}

\section{ARTICLE INFO \\ Article history: \\ Received on: 22/05/2015 \\ Revised on: 06/06/2015 \\ Accepted on: 14/07/2015 \\ Available online: $24 / 08 / 2015$}

Key words:

Lentinus squarrosulus,

carbon, nitrogen, fruit body

cultivation

\begin{abstract}
The present study aimed at cultivating the fruiting body of an edible mushroom identified as Lentinus squarrosulus collected from home garden of Tripura in Northeast India and for assessing the mycelium biomass growth using various carbon and nitrogen sources under submerged culture condition. The cultivation of the mushroom using paddy straw revealed dry weight of $0.25 \pm 0.02 \mathrm{~g}$ per fruit body with $21.83 \%$ of biological efficiency. Under submerged culture condition, fructose exhibited highest mycelium dry weight and yeast extract was found to be a best nitrogen source. The availability of the mushroom in the forest and homegarden of Tripura may be utilized for its commercial cultivation and inclusion in the local food. Fructose and yeast extract is recommended for high mycelial biomass production.
\end{abstract}

\section{INTRODUCTION}

Wild mushrooms are gaining importance in modern diet for their nutritional and pharmacological properties [1]. Many species of Lentinus are reported to be edible which can be cultivated on pasteurized as well as unpasteurized substrates [2]. Moreover, species of Lentinus have been reported to grow on various substrates [2-6].

The wild edible mushroom was collected from the homegarden of Tripura, Northeast India. A home garden refers to the traditional land use system around a homestead where several species of plants are grown and maintained by the household members and their products are primarily intended for the family consumption [7]. Homegarden with trees are one of agroforestry practices known to be ecologically sustainable and diversifies livelihood of local community.

In the present work, a naturally occurring strain of Lentinus squarrosulus (Mont.) Singer was collected from the wild and an attempt was made to cultivate the fruit body. In addition, the effect of different carbon and nitrogen sources on its mycelium growth and biomass production under submerged culture condition was assessed.

\footnotetext{
* Corresponding Author

Email: pannal1d[at]gmail.com
}

\section{MATERIALS AND METHODS}

\subsection{Sample collection}

An edible mushroom was collected from the homegarden of Tripura (latitude 23 $47^{\prime} 48.51$ ”; longitude $91^{\circ} 16^{\prime} 20.40^{\prime \prime} ; 24$ m.a.s.l) in Northeast India during April-October, 2013. Collected samples were packed in sterilized polythene zipped bag and brought to the laboratory for their identification. Identification of the specimens was carried out by considering various morphological characteristics [8] and molecular marker.

The mushroom was identified as Lentinus squarrosulus using the molecular marker sequences and the sequences were deposited in NCBI Gene Bank (Accession Number KP340800). Dried specimens were preserved as herbarium material (MCCT 03) in the Mycology and Plant Pathology Laboratory of the parent University.

\subsection{Tissue culture}

The material was washed thoroughly with autoclaved deionized water and $80 \%$ ethanol. It was then tap dried with sterile blotting paper. The middle portion between stipe and pileus of the mushroom was cut under sterile condition in the laminar air flow and inoculated in the malt extract agar slants and incubated at $25^{\circ} \mathrm{C}$ for two weeks. 


\subsection{Growth of mycelial biomass under submerged culture conditions with various carbon and nitrogen sources}

Lentinus squarrosulus were maintained on malt extract agar at $25^{\circ} \mathrm{C}$. All submerged culture was conducted in $100 \mathrm{ml}$ Erlenmeyer flasks filled with $30 \mathrm{ml}$ of basal synthetic medium. Fungal inocula were grown on synthetic medium consisting of the following components ( $\mathrm{g} / \mathrm{l}$ of deionized water): glucose-30.0, yeast extract-2, peptone-2.5, $\mathrm{MgSO}_{4} \cdot 7 \mathrm{H}_{2} \mathrm{O}-0.5, \quad \mathrm{Ca}\left(\mathrm{NO}_{3}\right)_{2}-0.5$, $\left(\mathrm{NH}_{4}\right)_{2} \mathrm{SO}_{2}-0.25, \quad \mathrm{FeCl}_{3}-0.010, \quad \mathrm{ZnSO}_{4}-0.005$, inositol-0.050, thiamine-0.0001, biotin-0.0005, folic acid-0.0001 and $\mathrm{CaCl}_{2}-$ 2.944. To study the effect of carbon sources on the fungal growth; in the basal synthetic medium, various carbon sources such as Carboxy methyl cellulose, Dextrose, Fructose, Lactose, Maltose, Starch, Sucrose and Xylose were tested. To study the effect of nitrogen sources, various amino acids and complex nitrogen sources such as Ammonium nitrate, Casein, Peptone, Urea, Yeast Extract, Alanine, Arginine, Asparagine, Glycine, Methionine, Tryptophan and Tyrosine were evaluated. Controls without carbon or nitrogen sources, respectively, were run in parallel. The flasks were inoculated with two week old precultures $\left(0.5 \mathrm{~cm}^{3}\right)$ and submerged cultures were kept stationary at $28^{\circ} \mathrm{C}$ for 14 days. The dry weight and growth rate was calculated.

\subsection{Cultivation}

For the production of spawn, $200 \mathrm{~g}$ of wheat grains was boiled with $500 \mathrm{ml}$ of water for 20 mins. The water was then drained off the grains and was surface dried for few hours. After drying the grains were thoroughly mixed with $2 \%$ calcium sulphate and $0.5 \%$ calcium carbonate. The mixture was filled in the $500 \mathrm{ml}$ conical flasks and plugged for autoclaving. The mycelium was inoculated in the wheat grain for the production of spawn in darkness for 3 weeks. At regular period of time the conical flasks were shaken for uniform growth of mycelium. The cultivation of fruit body of L. squarrosulus was initiated by soaking the paddy straw overnight. The water drained paddy straw was chopped (10 cm in length) and was autoclaved next day. The paddy straw was placed in $10 \mathrm{~kg}$ polythene bag in layers. The first layer of paddy straw was followed with the placement of wheat spawn alternately. The tied bag was incubated for three weeks at $32( \pm 2)^{\circ} \mathrm{C}$. The fruit bodies were harvested and the length and dry weight were determined after incubation period along with its biological efficiency [6].

\section{RESULTS AND DISCUSSION}

The source for the spawn production and inoculum for mycelium growth was obtained from the fruit body found growing in the dead mango tree in a home garden (Fig. 1a). The flushing of the fruit body after cultivation using paddy straw was observed after three weeks (Fig. 1b\&c). The stipe length, pileus diameter, dry weight and biological efficiency is presented in Table 1. The emergence of juvenile fruit bodies in malt extract media in the test tube was found after 60 days (Fig. 1d). Upadhyay and Rai (1999) reported wheat straw and paddy straw compost for the cultivation of L. squarrosulus. Oghenekaro et al. (2009) documented successful cultivation of $L$. squarrosulus on sawdust of five economic tropical tree species. The characterized mushroom was capable of utilizing all the tested carbon and nitrogen sources but the mycelial growth was greatly affected by the compound used in the nutrition medium. Carbon sources are major components of the nutrient medium, which must ensure the best growth of fungi. Submerged culture has a number of advantages including higher mycelial yield in a more compact space and shorter time, with fewer chances of contamination [9-11] which is now attracting attention as an alternative for efficient yield of mycelia and polysaccharide [12]. The mycelial growth of edible mushroom using different carbon and nitrogen source under submerged culture condition was tested using basal synthetic media. In case of carbon, maximum growth was observed using fructose as a source and minimum was carboxy methyl cellulose (Table 2).
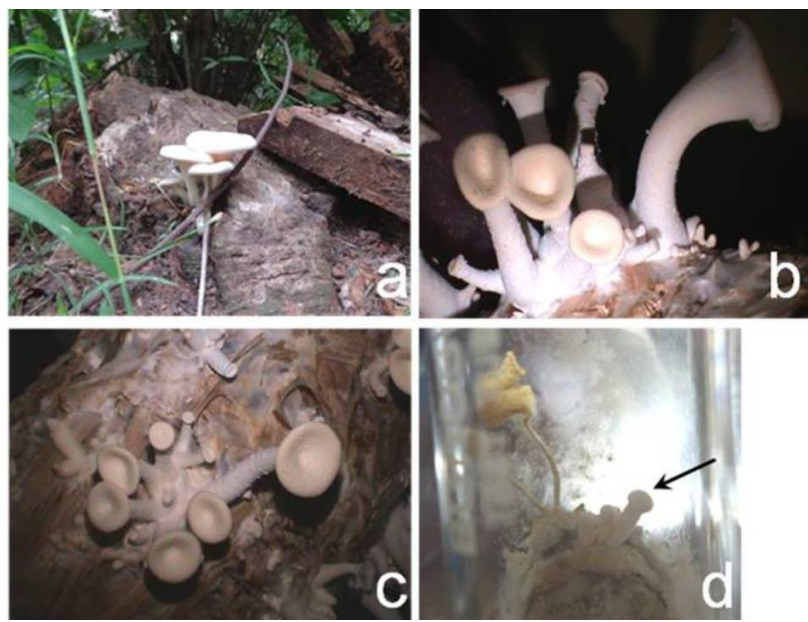

Fig. 1: (a) Mushroom fruit body growing in home garden. (b \& c) Fruit body arising from the paddy straw substrate under cultivation. (d) Fruit body developing from mycelium in malt extract media in test tube.)

Table 1. Fruit body features of an edible mushroom cultivated using paddy straw after first flushing.

\begin{tabular}{ccccccc}
\hline $\begin{array}{c}\text { Fresh } \\
\text { weight } \\
(\mathbf{g})\end{array}$ & $\begin{array}{c}\text { Dry } \\
\text { weight } \\
(\mathbf{g})\end{array}$ & $\begin{array}{c}\text { Stipe } \\
\text { length } \\
(\mathbf{c m})\end{array}$ & $\begin{array}{c}\text { Stipe } \\
\text { diameter } \\
(\mathbf{c m})\end{array}$ & $\begin{array}{c}\text { Pileus } \\
\text { diameter } \\
(\mathbf{c m})\end{array}$ & $\begin{array}{c}\text { No. } \\
\text { of } \\
\text { fruit } \\
\text { body }\end{array}$ & $\begin{array}{c}\text { Biological } \\
\text { efficiency } \\
(\%)\end{array}$ \\
\hline $1.14 \pm 0.10$ & $0.25 \pm 0.02$ & $2.55 \pm 0.13$ & $0.33 \pm 0.02$ & $3.15 \pm 0.15$ & 15 & 21.83 \\
\hline
\end{tabular}

Table 2: Mycelial growth of edible mushroom using different carbon source under submerged culture condition.

\begin{tabular}{lcc}
\hline Carbon Source & Dry weight $(\mathbf{g} / \mathbf{l})$ & Growth rate $(\mathbf{g} / \mathbf{l} / \mathbf{d a y})$ \\
\hline Control & $1.67 \pm 0.27$ & 0.12 \\
Carboxy methyl cellulose & $7.33 \pm 0.53$ & 0.52 \\
Dextrose & $14.95 \pm 0.75$ & 1.07 \\
Fructose & $17.45 \pm 0.02$ & 1.25 \\
Lactose & $15.63 \pm 0.57$ & 1.12 \\
Maltose & $17.12 \pm 1.55$ & 1.22 \\
Starch & $15.90 \pm 1.33$ & 1.14 \\
Sucrose & $16.62 \pm 0.75$ & 1.19 \\
Xylose & $12.70 \pm 0.20$ & 0.91 \\
\hline
\end{tabular}

The dry weight ranged between 4.20 and $17.45 \mathrm{~g} / \mathrm{l}$ using different carbon sources (Fig. 2). In case of nitrogen sources, maximum dry weight was observed in yeast extract and minimum was in ammonium nitrate (Table 3) and it ranged from 0.20 and 
$9.77 \mathrm{~g} / \mathrm{l}$ (Fig. 3). As reported earlier [13], fructose and yeast extract were proved to be more suitable than other carbon and nitrogen sources which is in agreement with the present study.

Table 3: Mycelial growth of edible mushroom using different nitrogen source under submerged culture condition.

\begin{tabular}{lcc}
\hline Nitrogen Source & Dry weight $(\mathbf{g} / \mathbf{l})$ & Growth rate $(\mathbf{g} / \mathbf{l} / \mathbf{d a y})$ \\
\hline Control & $0.34 \pm 0.04$ & 0.02 \\
Ammonium nitrate & $0.20 \pm 0.03$ & 0.01 \\
Casein & $5.37 \pm 1.30$ & 0.38 \\
Peptone & $5.68 \pm 1.45$ & 0.41 \\
Urea & $1.02 \pm 0.15$ & 0.07 \\
Yeast Extract & $9.77 \pm 0.10$ & 0.70 \\
Alanine & $0.50 \pm 0.30$ & 0.04 \\
Arginine & $0.90 \pm 0.63$ & 0.06 \\
Asparagine & $0.23 \pm 0.10$ & 0.02 \\
Glycine & $0.30 \pm 0.00$ & 0.02 \\
Methionine & $0.39 \pm 0.02$ & 0.03 \\
Tryptophan & $0.45 \pm 0.15$ & 0.03 \\
Tyrosine & $0.55 \pm 0.05$ & 0.04 \\
\hline
\end{tabular}

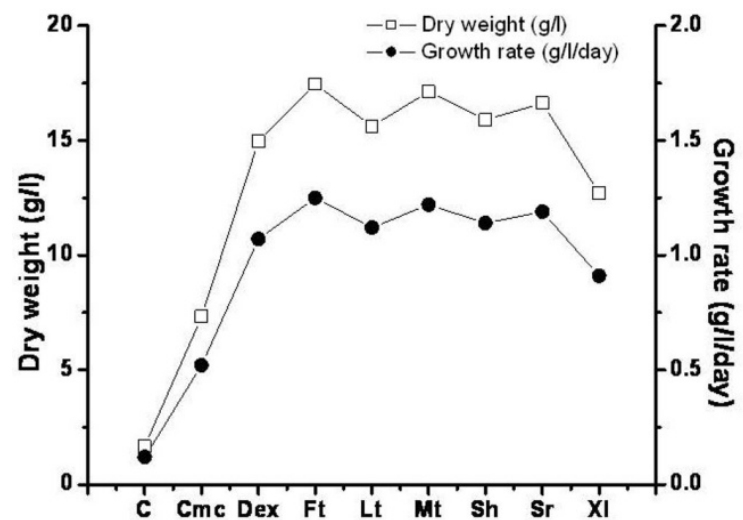

Fig. 2: Dry weight of mycelium using different carbon sources under submerged culture condition (C-Control, Cmc-Carboxy methyl cellulose, DexDextrose, Ft-Fructose, Lt-Lactose, Mt-Maltose, Sh-Starch, Sr-Sucrose, XlXylose.

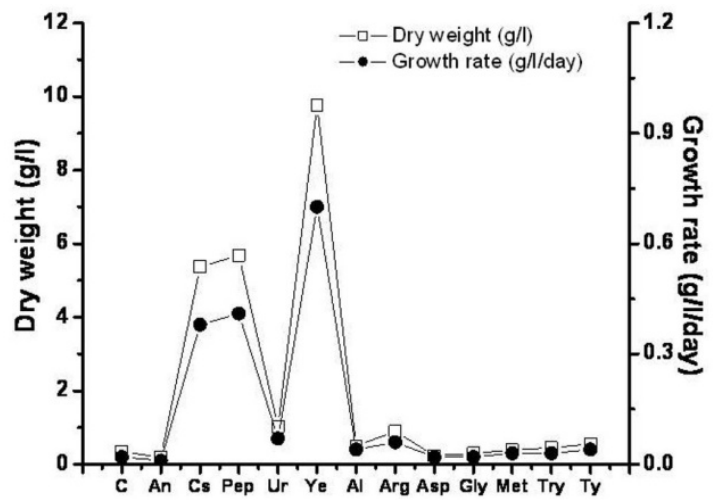

Fig. 3: Fig. 3: Dry weight of mycelium using different nitrogen sources under submerged culture condition (C-Control, An-Ammonium nitrate, Cs-Casein, Pep-Peptone, Ur-Urea, Ye-Yeast Extract, Al-Alanine, Arg-Arginine, AspAsparagine, Gly-Glycine, Met-Methionine, Try-Tryptophan, Ty-Tyrosin.

\section{CONCLUSION}

The results of the present study on the local mushroom supplements the fact that $L$. squarrosulus can be successfully cultivated in the laboratory on lignocellulosic substrates such as paddy straw. This can be widely exploited for industrial use in the production of mycelium with fructose and yeast extract as carbon and nitrogen sources, respectively.

\section{ACKNOWLEDGEMENTS}

The authors are thankful to Head, Department of Botany, Tripura University for the facilities. ARD is grateful to DBT, Govt. of India for the fellowship and to State Biotech Hub for the laboratory facilities.

\section{REFERENCES}

1. Elmastas M, Isildak O, Turkekul I and Temur N. Determination of antioxidant activity and antioxidant compounds in wild edible mushrooms. J. Food Compos. Anal. 2007; 20:337-345.

2. Morais MH, Ramos AC, Matou N and Santous OEJ. Note: production of shitake mushroom (Lentinus edodes) on lignocellulosic residues. Food Sci. Technol. Int. 2000; 6:123-128.

3. Upadhyay RC and Rai RD. Cultivation and nutritive value of Lentinus squarrosulus. Mushroom Research. 1999; 8(2):35-38.

4. Adesina FC, Fasidi IO and Adenipekun OC. Cultivation and fruit body production of Lentinus squarrosulus Mont. (Singer) on bark and leaves of fruit trees supplemented with agricultural waste African. Journal of Bio technology. 2011; 10: 4608-4611.

5. Oghenekaro AO, Okhuoya JA and Akpaja EO. Growth of Lentinus squarrosulus (M.) Singer on sawdust of different tropical tree species. African Journal of Food Science. 2009; 3(1):007-010.

6. Atri NS and Lata. Studies for culturing and cultivation of Lentinus cladopus Lév. Mycosphere. 2013; 4:675-682.

7. Devi NL and Das AK. Diversity and utilization of tree species in Meitei homegardens of Barak Valley, Assam. Journal of Environmental Biology. 2013; 34:211-217.

8. Pegler DN. A Preliminary Agaric Flora of East Africa. Kew Bulletin. Addit. Ser. VI. 1977.

9. Yang FC, Huang HC and Yang MJ. The influence of environmental conditions on the mycelial growth of Antrodia cinnamomea in submerged cultures. Enzyme and Microbial Technology. 2003; 33:395-402.

10. Pokhrel CP and Ohga S. Submerged culture conditions for mycelial yield and polysaccharides production by Lyophyllum decastes. Food Chemistry. 2007; 105: 641-646.

11. Liu RS, Li DS, Li HM and Tang YJ. Response surface modeling the significance of nitrogen source on the cell growth and Tuber polysaccharides production by submerged cultivation of Chinese truffle Tuber sinense. Process Biochem. 2008; 43: 868-876.

12. Wang F, Zhang J, Hao L, Jia S, Ba J and Niu S. Optimization of Submerged Culture Conditions for Mycelial Growth and Extracellular Polysaccharide Production by Coriolus versiolor. Bioprocessing and Biotechniques. 2012; 2:124

13. Gbolagade JS, Fasidi IO, Ajayi EJ and Sobowale AA. Effect of physico-chemical factors and semi-synthetic media on vegetative growth of Lentinus subnudus (Berk.), an edible mushroom from Nigeria. Food Chemistry. 2006; 99: 742-747.

\section{How to cite this article:}

Das A. R., Borthakur M., Saha A. K., Joshi S. R., Das P. Growth of mycelial biomass and fruit body cultivation of Lentinus squarrosulus collected from home garden of Tripura in Northeast India. J App Biol Biotech. 2015; 3 (04): 017-019. 